\title{
The Effects of Sociodemographic Characteristics on Chinese Elders' Perception of the Image of Ageing
}

\author{
Nelson Chow and Xue Bai \\ Department of Social Work and Social Administration, The University of Hong Kong, Pokfulam, Hong Kong \\ Correspondence should be addressed to Xue Bai, baixue@hkusua.hku.hk
}

Received 6 July 2010; Accepted 24 September 2010

Academic Editor: Abbas Bhuiya

Copyright () 2011 N. Chow and X. Bai. This is an open access article distributed under the Creative Commons Attribution License, which permits unrestricted use, distribution, and reproduction in any medium, provided the original work is properly cited.

A positive image of elderly people is found to be contributive to successful ageing. This paper reports a study that aims at revising and validating Image of Ageing Scale in a modern Chinese context and finding out how socio-demographic factors have impacted the latter's perception of the image of ageing. Confirmatory factor analysis supported the five-factor model suggested from exploratory factor analysis which produced good psychometric properties. Based on the two-cluster solution from the twostep cluster analysis on the image of ageing, results of both the Chi-square and the one-way ANOVA tests confirmed that age, residence location, marital status, working status, living arrangement, neighborhood relationships, illness and daily activity were significant predictors of elders' image of ageing. Logistic results further indicated that some predictors were not statistically significant in the multivariate analysis, whilst being urban, lonely, suffering from severe chronic illnesses, and showing little interests in daily activities, were identified as potent factors resulting in a negative image of ageing. Other than suggesting the Revised Chinese Version of the Image of Ageing Scale (IAS-C) could be used in a Chinese society, our findings also led to a number of recommendations to promoting a positive image among the Chinese elderly.

\section{Introduction}

The world's population is ageing rapidly. Declining fertility rates combined with steady lengthening of life expectancies over the latter half of the 20th century have tripled the number of elderly people all over the World; it is further projected that the number will triple again over the next 50 years [1]. As the most populous country in the world, China is also experiencing a dramatic change in its age structure. In 2008, the number of elderly people aged 65 and above in China reached more than 109.56 million, or eight percent of the population, with an annual growth rate of around three percent [2]. It is noteworthy that while modernization, together with population ageing, has happened in Western countries for more than a century, China would be confronted with the challenges of ageing in a much shorter period, and before she becomes "rich" [3]. The challenges of fostering successful ageing among the growing elderly population in China include helping them to avoid diseases and disabilities, to maintain high physical and cognitive functions, and to sustain their interests in social and productive activities with a positive attitude towards life itself $[4,5]$.

Other than the wide array of biological factors that have been identified to explain the physical and cognitive declines in old age, studies have suggested that elderly people who think positively about themselves, instead of accepting negative stereotyping, would play an important role in successful ageing. To be specific, a positive image held by elderly people has been found to be predictive of better memory and hearing performances [6-8], lower chance to suffer from cardiovascular diseases [9], less depressive symptoms, faster walking, stronger will to live, and better survival over time [10-12]. Though psychological wisdom suggests that contact with reality is significant to mental health, a bit of unrealistic but positive image of oneself and of the outside environment might also make people less unhappy $[13,14]$. Elderly people who view themselves positively are thus found more likely to be happy and having a better quality of life $[15,16]$.

However, as the society becomes more modernized, elderly people begin to be portrayed by the media as a group 
who are passive in character, frail, stubborn, weak, and poor while these views are often shared by the younger generations [17-20]. As for elderly people in Chinese communities, especially those in China itself, so far, efforts are few to examine their image, either perceived by themselves or by others [11, 21]. To account for this lack of knowledge about the image of ageing in Chinese communities is the assumption that since respecting the old is so much treasured among the Chinese that elderly people there should not have a negative image of themselves, nor of their peers [22]. However, the respect for elderly people, especially in its traditional form, is known to have gradually faded away in Chinese communities, and this is also true of the situation in China, particularly as it opened up and quickened its modernization process after 1978 [23-27]. Furthermore, as China has to "compress" her modernization process in a short period of time, sacrifices have to be made for the rapid decline of some of its traditional values, like respecting the old. Similar experiences of diminishing image of the elderly have also been reported in other East Asian societies [28].

This study represents an attempt to fill a research gap in revising and validating Levy et al.s [29] Image of Ageing Scale as it is modified and applied to a Chinese community. Another effort is to identify the Sociodemographic factors that could be predictive of the ageing image. Previous studies have successfully located some of the Sociodemographic factors that possess the power to predict the mental health conditions of older populations [30]. These include age [31], socioeconomic status [32], and living arrangement [33]. But none of the above has yet to be found directly related to the image of ageing. This study, besides testing the application of the Revised Chinese Version of Image of Ageing Scale (IASC) to Chinese communities, aims to find out the sociodemographical factors that would be determinant of this image. We hope that our findings would contribute towards the formulation of relevant policies for the promotion of a positive image among elderly people in Chinese communities.

\section{Research Methodology}

2.1. Sampling. This study was carried out in Wuhan, an industrialized city in the central part of China. As the capital of Hubei province, Wuhan is situated along the Yangtze River. With more than eight million residents, it is one of the cities in China experiencing rapid population aging. Till 2009, the number of elderly people aged 60 and above in Wuhan is about 1.14 million, accounting for 14 percent of the total population [34]. Wuhan consists of 13 districts with seven being urban and six suburban [35].

The primary criteria for the selection of participants in our study were that they must be local residents, physically living in Wuhan, and aging 60 years or above. Multistage Cluster Sampling with Stratification was employed. As a first step, we randomly selected five out of the 13 districts in Wuhan, with three classified as urban and two suburban. We then subdivided each district into census blocks and created a list of elders living in each of the selected blocks. To estimate a proper sample size, we employed the formula put forth by [36] " $n=P(1-P)(z / E)^{2}$," in which $n$ represents
TABLE 1: Sociodemographic characteristics of participants.

\begin{tabular}{|c|c|c|}
\hline Characteristics & Categories & $N(\%)$ \\
\hline \multirow{2}{*}{ Urban-rural residence } & Urban & $295(66.3)$ \\
\hline & Rural & $150(33.7)$ \\
\hline \multirow{3}{*}{ Age group } & Young old (60-69) & $267(60.0)$ \\
\hline & Mid-old (70-79) & $127(28.5)$ \\
\hline & Old-old (above 80) & $51(11.5)$ \\
\hline \multirow{2}{*}{ Gender } & Male & $224(50.3)$ \\
\hline & Female & $221(49.7)$ \\
\hline \multirow{3}{*}{ SES } & Low & $141(31.9)$ \\
\hline & Moderate & $221(50.0)$ \\
\hline & High & $80(18.1)$ \\
\hline \multirow{3}{*}{ Marital status } & Single & $27(6.1)$ \\
\hline & Widowed & $113(25.5)$ \\
\hline & Married & $304(68.5)$ \\
\hline \multirow{3}{*}{ Working status } & $\begin{array}{l}\text { Retired or no longer } \\
\text { working }\end{array}$ & $280(63.2)$ \\
\hline & Still employed & $144(32.5)$ \\
\hline & Doing other things & $19(4.3)$ \\
\hline \multirow{4}{*}{ Living arrangement } & Elderly homes & $49(11.0)$ \\
\hline & Alone & $61(13.7)$ \\
\hline & Only with spouse & $131(29.4)$ \\
\hline & $\begin{array}{l}\text { With more than one } \\
\text { generation }\end{array}$ & $204(45.8)$ \\
\hline \multirow{3}{*}{$\begin{array}{l}\text { Neighbourhood } \\
\text { relationship }\end{array}$} & $\mathrm{Bad}$ & $59(13.3)$ \\
\hline & Normal & $253(57.2)$ \\
\hline & Good & $130(29.4)$ \\
\hline \multirow{3}{*}{ Illness } & No illness & $161(36.2)$ \\
\hline & Moderate & $174(39.1)$ \\
\hline & Severe & $110(24.7)$ \\
\hline \multirow{3}{*}{ Daily activity } & Inactive & $63(14.2)$ \\
\hline & Moderate & $237(53.3)$ \\
\hline & Active & $145(32.6)$ \\
\hline
\end{tabular}

the size of the sample, $z$ stands for the standard normal value corresponding to the desired level of confidence (if a confidence level of $95 \%$ is desired, the value of $z$ is 1.96), and $E$ equals the maximum allowable error $=0.05$, and $P=.5$, if no estimate is available. Hence, at least 384 participants should be approached as interviewees in the survey. Considering that there might be some incomplete questionnaires with missing value, we totally sent out 500 questionnaires to our potential respondents randomly selected in each block. 445 elderly people (we call them participants in our study) were successfully interviewed as a result, almost half male and half female, whose answers had less than five percent missing value. Of this group, about 34 percent were coming from rural Wuhan while 66 percent from urban. The great majority of our participants were community dwelling but for purpose of comparison, we deliberately included approximately 10 percent of our participants who were living in institutions. Some social and demographic characteristics of our participants are shown in Table 1. 


\subsection{Data Collection}

2.2.1. Pilot Study. Envisioning the difficulties that might be involved in adapting Levy et al.'s [29] Image of Aging Scale to a Chinese population, we conducted 30 in-depth interviews prior to the actual implementation of the study. 15 elders from urban and 15 from rural Wuhan were selected whom we considered might meet our criteria. Imitating the questions constructed by Levy et al. [29] to measure the image of ageing, we asked our participants to respond to the following two questions: "when you try to describe yourself, what are the first five words or phrases that would come to mind?" "When you think of elderly people in general (not including yourself), what are the first five words or phrases that come to mind?" Since we did not intend to develop an entire new "Image of Ageing" scale on elderly people in China, but to modify the one that has been validated by Levy et al. [29], we retained, as much as possible, the original items developed by them, in accordance with the words and phrases given by our participants in the pilot study. The scale, so devised, was subsequently tested in another pilot with 20 older adults to ensure its ease of understanding. Some of our participants complained that the word form of our scale, without specifying the target of evaluation, often made them feel confused, we thus turned the items into statements, making sure that our participants were well aware of rail of what we were measuring.

2.2.2. Main Study. Respondents in our study were required to sign a consent form to indicate that they did fully understand the purpose of the study. However, owing to the fact that our participants were either poor in vision or had hardly received any education, we decided at the end to carry out face-to-face questionnaire interviews, instead of asking our participants to fill out a questionnaire by themselves. Five students were recruited as interviewers from the Department of Sociology of Huazhong University of Science and Technology in Wuhan. They were clearly informed of the objectives and purposes of the study, and after several sessions of training, the survey was conducted in the summer of 2009. Meetings and supervision sessions were frequently held during the course of the survey, and interviewers were encouraged to offer their views to avoid any misunderstandings that would lower the quality of the results.

\subsection{Measurements}

2.3.1. Sociodemographic Characteristics. The demographic variables commonly examined in research include race, gender, age, income, educational attainment, employment status, home ownership, and residence location. Other than the above, marital status has been found in a number of studies to exert an influence on the health and mortality rate of older adults [37-39]; living arrangements, family ties, and neighborhood relationships are other factors that are considered to be of particular importance on shaping the image of the elderly living in collectivistic societies like China [40]; lastly, illnesses suffered by elderly people, as well as the level of their daily activities, is viewed as important to predict their well-being. In summary, Sociodemographic variables that would be examined in this study as for their impact on the image of ageing include residence location, age, gender, education, income, previous employment, marital status, working status, living arrangement, neighborhood relationships, health, and levels of daily activities.

Our participants consisted of three age groups: youngold (60 70), middle-old (71 80), and old-old (above 80). Their socioeconomic conditions were measured in accordance with their educational attainments, incomes, and occupational statuses. Of these three, we further divided them into three levels. For those achieving high scores in all the three aspects and those high in two of them and moderate in one, we classified them all as attaining high socioeconomic status; those who were low in all three and those low in two and moderate in one were all labeled as possessing low socioeconomic status; while the rest were all classified as having moderate socioeconomic status. Whether they were presently married, divorced or bereaved, or had never married was reported as their marital status. Working status refers to their current employment status, whether retired, still employed, or doing something else. Their living arrangement was measured by whether they were living in elderly homes, alone, living with spouse, or in extended families. Neighborhood relationships were rated by elderly participants themselves, divided into bad, normal, or good. Health status was determined by chronic diseases suffered by our participants, and they were divided into three groups in accordance with the number conceived by them. Similarly, participants were divided into three groups according to the number of daily activities that they have participated per day.

\subsubsection{Revised Chinese Version of Image of Ageing Scale (IAS-} $C)$. The image of ageing examined in this study refers to the collection of attitudes and judgments elderly people hold towards their own ageing process and that they hold about their peers. The scale, known as the Revised Chinese Version of Levy et al.'s Image of Ageing Scale (IAS-C), consists of 28 items, divided into two same sets of variables, with one measuring elderly people's self-perception and the other elders' perception of their peers. The confirmatory factor analysis (CFA) on the dimension of the self-image of ageing $\left(\chi^{2}=75.285 ; \mathrm{df}=65 ; P=.180\right.$; CFI $=0.973$; TLI $=0.962$; RMSEA $=0.026)$ supported the five-factor model with 14 items, suggested by the exploratory factor analysis (EFA). To determine whether the factor structure of the peer image of ageing is consistent with the model (five-factor model) suggested by the results from the selfimage of ageing dimension, we further conducted CFA with the 14 items in the dimension of peer image of ageing; the result also showed an acceptable overall fit with $\chi^{2}=$ 120.319, df $=65, P<.001$, CFI $=0.901$, TLI $=0.862$, $\mathrm{GFI}=0.963$, and RMSEA $=0.044$. Thus, the factorial structure, which has been confirmed in the domain of selfimage of ageing, is also confirmed in the domain of peer image of ageing. The reliability results showed that the scale has acceptable internal consistency for both the overall scale 
TABle 2: Principal components EFA on IAS-C (self-image of ageing): varimax rotated factor structure and communalities for each item $(N=223)$.

\begin{tabular}{|c|c|c|c|c|c|c|}
\hline \multirow{2}{*}{ Item $=14(N=227)$} & \multirow{2}{*}{ Communality } & \multicolumn{5}{|c|}{ Component } \\
\hline & & 1 & 2 & 3 & 4 & 5 \\
\hline \multicolumn{7}{|l|}{ General physical health } \\
\hline I walk slowly & 0.588 & 0.739 & 0.118 & 0.018 & 0.121 & 0.117 \\
\hline I am healthy & 0.566 & 0.721 & -0.070 & 0.140 & 0.011 & 0.147 \\
\hline I am full of life & 0.639 & 0.699 & 0.352 & 0.151 & 0.037 & 0.041 \\
\hline \multicolumn{7}{|l|}{ Social virtues } \\
\hline I am family-oriented & 0.653 & -0.051 & 0.786 & 0.011 & 0.145 & 0.109 \\
\hline I am tough & 0.595 & 0.284 & 0.688 & 0.113 & -0.113 & -0.123 \\
\hline I can rely on myself & 0.492 & 0.333 & 0.481 & 0.358 & 0.063 & -0.130 \\
\hline \multicolumn{7}{|l|}{ Life attitudes } \\
\hline I have positive outlook & 0.636 & 0.218 & -0.167 & 0.748 & 0.033 & 0.016 \\
\hline I am well groomed & 0.579 & -0.013 & 0.199 & 0.727 & 0.090 & 0.044 \\
\hline I have strong will to live & 0.491 & 0.112 & 0.300 & 0.543 & -0.030 & 0.305 \\
\hline \multicolumn{7}{|l|}{ Psychosocial status } \\
\hline I am lonely & 0.646 & 0.015 & 0.225 & -0.097 & 0.762 & -0.067 \\
\hline I am helpless & 0.610 & 0.000 & 0.031 & 0.085 & 0.729 & 0.265 \\
\hline I am sentimental & 0.659 & 0.258 & -0.314 & 0.225 & 0.665 & 0.032 \\
\hline \multicolumn{7}{|l|}{ Cognition } \\
\hline I am wise & 0.713 & 0.015 & 0.010 & 0.178 & 0.050 & 0.824 \\
\hline I am senile & 0.558 & 0.291 & -0.059 & -0.034 & 0.136 & 0.671 \\
\hline$\%$ Variance & 60.179 & 22.326 & 12.575 & 9.535 & 8.327 & 7.416 \\
\hline
\end{tabular}

Kaiser-Meyer-Olkin measure of sampling adequacy $=0.746$;

$P$ value of Bartlett's test of sphericity $<.001$.

(Cronbach's alpha $=0.729$ ) and the subscales (alphas ranged from 0.506 to 0.651 ). Test-retest reliability reached 0.871 . Criteria-referenced validity of the self-image dimension was demonstrated by correlations with the number of daily activities and chronic illnesses in the expected directions. Results thus enabled us to use the same contents to examine the dimension of elderly people's peer image as Levy et al. [29] had done for her Image of Ageing Scale.

2.4. Statistical Analysis. Data entry and analysis was done by using the Statistical Package for Social Sciences (SPSS) version 17.0 and Amos version 17.0. EFA and CFA was first carried out to validate IAS-C along with finding out its psychometric properties. A cluster analysis was then performed to identify the different groups who differed in their perception of the image of ageing, based on the scores obtained from the confirmed factors. Cross-tabulation with chi-Square tests, as well as one-way ANOVAs, was then conducted for the purpose of locating cluster membership with the selected Sociodemographic characteristics. Finally, binary logistic regression was employed through regression of the dichotomous variables of cluster membership on a set of independent variables selected from previous analysis. This enabled us to ascertain whether these characteristics, which were significantly associated with either the negative or positive groups, were statistically significant in a multivariate context.

\section{Results}

3.1. Validation of the IAS-C. The principal components exploratory factor analysis (EFA) with varimax rotation and Kaiser normalization reveals that the Kaiser-Meyer-Olkin measure of sampling adequacy is 0.746 and Barlett's test of sphericity is statistically significant at $P<.0001$, hence supporting the factorability of the correlation matrix [4143]. EFA, based on a random half of our sample, suggests a 5 -factor solution with 14 items (i.e., the final version of the 14-item self-image of ageing), accounting for $60.2 \%$ of the total variance. The varimax rotated factor loadings and communalities for each item are presented in Table 2. The highest loadings for each variable are all significant, ranging from 0.482 to 0.824 . We observed that there is no cross-loading for whichever variable as having significant loadings $(>0.40)$ on several factors. Finally, communalities of all variables are more than or very close to 0.50 , ensuring that all variables are adequately accounted for by this factor solution [42].

Component 1, labeled "general physical health," accounted for $22.33 \%$ of the total variance; Component 2, 
TABLE 3: Distribution of regrouped participants' perception of their own image between the clusters.

\begin{tabular}{|c|c|c|c|c|c|c|}
\hline & $n$ & Self-GPH & Self-SV & Self-LA & Self-PSS & Self-COG \\
\hline Cluster 1 & 265.000 & 9.053 & 11.898 & 11.234 & 9.539 & 5.879 \\
\hline Cluster 2 & 180.000 & 12.000 & 13.656 & 12.628 & 11.016 & 6.656 \\
\hline Independent sample $t$-test & & $13.853^{* * *}$ & $11.201^{* * *}$ & $7.892 * * *$ & $6.084^{* * *}$ & $4.378^{* * *}$ \\
\hline Degree of freedom & & 443 & 443 & 397 & 392 & 443 \\
\hline
\end{tabular}

$P<.001^{* * *} ; P<.01^{* *} ; P<.05^{*}$.

TABLE 4: Distribution of regrouped participants' perception of their peer's image between the clusters.

\begin{tabular}{|c|c|c|c|c|c|c|}
\hline & $n$ & Peer-GPH & Peer-SV & Peer-LA & Peer-PSS & Peer-COG \\
\hline Cluster 1 & 265.000 & 8.324 & 11.030 & 10.789 & 7.906 & 5.067 \\
\hline Cluster 2 & 180.000 & 9.844 & 12.767 & 12.372 & 9.155 & 5.433 \\
\hline Independent sample $t$-test & & $8.886^{* * *}$ & $12.572^{* * *}$ & $10.668^{* * *}$ & $6.349^{* * *}$ & $2.749^{* *}$ \\
\hline Degree of freedom & & 373 & 443 & 443 & 443 & 443 \\
\hline
\end{tabular}

$P<.001^{* * *} ; P<.01^{* *} ; P<.05^{*}$.

labeled "social virtues" accounted for $12.58 \%$ of the total variance; Component 3, labeled "life attitudes," accounted for $9.54 \%$ of the total variance; Component 4, labeled "psychosocial status," accounted for $8.33 \%$ of the total variance; Component 5, labeled “cognition," accounted for $7.42 \%$ of the total variance.

Results of the confirmatory factor analysis on the other random half of our sample showed a good overall fit $\left(\chi^{2}=\right.$ $75.285, \mathrm{df}=65, P=.180(>.05)$, CFI $=0.973$, TLI $=$ 0.962 , and RMSEA $=0.026$ ) of our modified five-factor model, compared with either the nine-factor model or the two-factor model suggested by Levy et al.'s [29] Image of Ageing Scale. The factor structure is constructed by using our data as a base and appears to be more general than previously assumed. For example, conceptual categories like "activity," "physical health," and "death" merged as one factor and we called it "general physical health." Similarly, conceptual categories like "appearance," "personality," and "will to live" merged as another new factor and we named it "attitude towards life." "Cognition" was retained while some of the items from the categories of "dependence" and "personality," as well as a self-added item "tough," formed another important factor "social virtues." Finally, "helpless," "lonely" from relationships, and "sentimental," frequently used by the Chinese elderly in their daily conversations, made up another factor "psychosocial status." The reliability test results showed that the scale has acceptable internal consistency for the overall scale (Cronbach's alpha $=0.729$ ), as well as the subscales (alphas ranged from 0.506 to 0.651 ). Test-retest reliability reaches 0.871 . Its criteria-referenced validity was demonstrated by correlations with illnesses and interests in daily activities, in the expected directions. CFA was further conducted with the 14 items in the dimension of peer image of ageing, the result also showed an acceptable overall fit with $\chi^{2}=120.319, \mathrm{df}=65, P<.001, \mathrm{CFI}=0.901$, $\mathrm{TLI}=0.862$, GFI $=0.963$, and RMSEA $=0.044$. Thus, it allows us to use the same contents to examine the dimension of elderly people's peer image as Levy et al. [29] did in her Image of Ageing Scale.
3.2. Cluster Analysis on Elderly People's Perception of Image of Ageing. Our purpose is to partition our elderly participants into clusters, based on their positivity or negativity of their image of ageing and to explore the possible impacts of their Sociodemographic characteristics on the positive-negative division. We thus selected the scores of the above-confirmed five dimensions of both their own perception of the selfimage and their perception of their peers' image as clustering variables. Since multicollinearity might act as a weighting process, not apparent to the observer though affecting the analysis, we further examined the correlations between the clustering variables for substantial multicollinearity before conducting the cluster analysis. We observed that there is no strong correlation $(>0.5)$ between these variables and more than half of the correlation coefficients are less than 0.2 . Owing to the equal numbers of variables in each set of the image (self-image and peer image), the potential minor multicollinearity effect would probably be cancelled out.

Compared with traditional clustering techniques, the two-step cluster analysis employed has several desirable features, including its ability to handle both categorical and continuous variables and to automatically select the number of clusters and its applicability of large data files [44]. Thus, the SPSS two-step cluster method is found to be suitable. Cluster distances were estimated using the log-likelihood function so that cluster membership was assigned in accordance with the maximum decrease in log likelihood. This approach allowed for model comparison and the decision of the optimal number of clusters by means of the Bayesian information criterion (BIC).

A two-cluster solution was hence obtained in this study $(\mathrm{BIC}=8926)$. The distribution of the five components for both elderly participants' perception of their self-image and their peer image between the clusters is shown in Tables 3 and 4 . Cluster 1 residents $(n=180)$ are found to have higher scores of the image of ageing in terms of their general physical health, social virtues, life attitudes, psychosocial status, and cognition while cluster 2 residents $(n=265)$ are found to have relatively lower scores in all areas of the image of ageing. 
TABLE 5: Cross-tabulations between cluster membership for image of ageing and Sociodemographic characteristics with chi-square tests.

\begin{tabular}{|c|c|c|c|c|}
\hline \multirow{4}{*}{ Characteristics } & \multicolumn{4}{|c|}{ Cluster membership } \\
\hline & \multirow{2}{*}{\multicolumn{2}{|c|}{$\begin{array}{l}\text { Negative image group } \\
\qquad(N=265)\end{array}$}} & \multirow{2}{*}{\multicolumn{2}{|c|}{$\begin{array}{l}\text { Positive image group } \\
\qquad(N=180)\end{array}$}} \\
\hline & & & & \\
\hline & $N$ & $\%$ & $N$ & $\%$ \\
\hline Urban-rural residence & \multicolumn{4}{|c|}{$\left(\chi^{2}=11.128 ; \mathrm{df}=1 ; P=.001\right)$} \\
\hline Urban & 192 & 65.085 & 103 & 34.915 \\
\hline Rural & 73 & 48.667 & 77 & 51.333 \\
\hline $\operatorname{Age}(y r)(60-92)$ & \multicolumn{4}{|c|}{$\left(\chi^{2}=5.504 ; \mathrm{df}=2 ; P=.064\right)$} \\
\hline Young-old (60-69) & 149 & 55.805 & 118 & 44.195 \\
\hline Mid-old (70-79) & 79 & 62.205 & 48 & 37.795 \\
\hline Old-old (above 80) & 37 & 72.549 & 14 & 27.451 \\
\hline Gender & \multicolumn{4}{|c|}{$\left(\chi^{2}=0.072 ; \mathrm{df}=1 ; P=.788\right)$} \\
\hline Male & 132 & 49.811 & 92 & 51.111 \\
\hline Female & 133 & 50.189 & 88 & 48.889 \\
\hline Social-economic status & \multicolumn{4}{|c|}{$\left(\chi^{2}=4.734 ; \mathrm{df}=2 ; P=.094\right)$} \\
\hline Low & 75 & 53.191 & 66 & 46.809 \\
\hline Moderate & 142 & 64.253 & 79 & 35.747 \\
\hline High & 45 & 56.250 & 35 & 43.750 \\
\hline Marital status & \multicolumn{4}{|c|}{$\left(\chi^{2}=11.254 ; \mathrm{df}=2 ; P=.004\right)$} \\
\hline Single & 22 & 81.481 & 5 & 18.519 \\
\hline Widowed & 76 & 67.257 & 37 & 32.743 \\
\hline Married & 166 & 54.605 & 138 & 45.395 \\
\hline Working status & \multicolumn{4}{|c|}{$\left(\chi^{2}=12.716 ; \mathrm{df}=2 ; P=.002\right)$} \\
\hline Retired or no longer working & 184 & 65.714 & 96 & 34.286 \\
\hline Still employed & 70 & 48.611 & 74 & 51.389 \\
\hline Doing other things & 9 & 47.368 & 10 & 52.632 \\
\hline Living arrangement & \multicolumn{4}{|c|}{$\left(\chi^{2}=14.501 ; \mathrm{df}=3 ; P=.002\right)$} \\
\hline Elderly home & 38 & 77.551 & 11 & 22.449 \\
\hline Alone & 43 & 70.492 & 18 & 29.508 \\
\hline Only with spouse & 78 & 59.542 & 53 & 40.458 \\
\hline With more than one generation & 106 & 51.961 & 98 & 48.039 \\
\hline Neighbourhood relationship & \multicolumn{4}{|c|}{$\left(\chi^{2}=10.831 ; \mathrm{df}=2 ; P=.004\right)$} \\
\hline $\mathrm{Bad}$ & 42 & 71.186 & 17 & 28.814 \\
\hline Normal & 158 & 62.451 & 95 & 37.549 \\
\hline Good & 63 & 48.462 & 67 & 51.538 \\
\hline Illness & \multicolumn{4}{|c|}{$\left(\chi^{2}=39.955 ; \mathrm{df}=2 ; P=.000\right)$} \\
\hline No illness & 70 & 43.478 & 91 & 56.522 \\
\hline Moderate & 105 & 60.345 & 69 & 39.655 \\
\hline Severe & 90 & 81.818 & 20 & 18.182 \\
\hline Daily activity & \multicolumn{4}{|c|}{$\left(\chi^{2}=20.106 ; \mathrm{df}=2 ; P=.000\right)$} \\
\hline Inactive & 45 & 71.429 & 18 & 28.571 \\
\hline Moderate & 155 & 65.401 & 82 & 34.599 \\
\hline Active & 65 & 44.828 & 80 & 55.172 \\
\hline
\end{tabular}

$P<.001^{* * *} ; P<.01^{* *} ; P<.05^{*}$.

To facilitate further analyses, we named these two clusters as "the positive image group," and "the negative image group" respectively. To examine the stability of the cluster results, we did another round of cluster analysis for a random half of our sample $(N=223)$. The same clustering variables were used to group our elderly participants. We got a two-cluster solution with 65 belonging to the positive image cluster while the remaining 158 in the negative image cluster. In comparison to their cluster membership previously obtained from the entire sample, we observed that 13 percent of our 
TABLE 6: Means comparison of perception of self-image of ageing and that of peers among different characteristic groups.

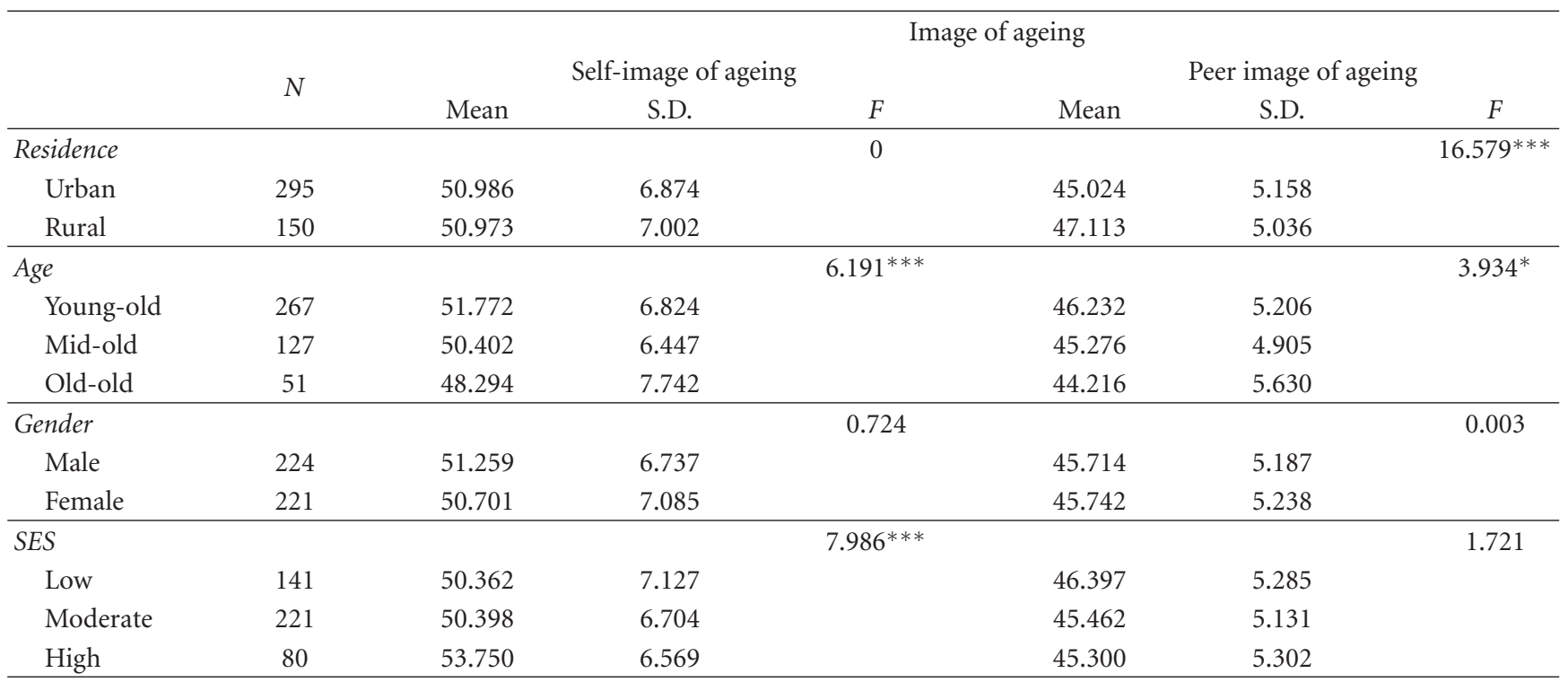

$P<.001^{* * *} ; P<.01^{* *} ; P<.05^{*}$.

participants belonged now to a different group, with 27 of them originally belonging to the positive image group now grouped into the negative image cluster, with only two originally belonging to the negative image group now switched to the positive image group. As suggested by Hair et al. [42], such results between 10 and 20 percent changing to a different group should be considered as a stable solution.

The independent-samples $t$-test indicates that the mean scores of the five factors on elderly people's perception of their self-image of the positive group are 12.000, 13.656, $12.628,11.016,6.656$, respectively, while the means on that of the negative group are 9.053, 11.898, 11.234, 9.539, and 5.879. An interesting observation is that more than $75 \%$ of our participants held a more positive self-image than what they had of their peers, indicating the existence of selfenhancement bias. This confirms previous findings in that people are motivated to view themselves more positively on a variety of attributes and capabilities than how they view their peers or what others view of them $[13,45]$. Obviously, the means between the positive and negative groups differed significantly at the $P<.001$ level on all the above five factors. The $t$-test shows that the means of the five factors in the positive group are significantly higher than those of the negative group.

To further validate the differences between the Sociodemographic characteristics of our participants in both the positive and the negative groups, to identify suitable candidate variables for subsequent logistic regression analysis, and to establish valid criteria for cluster solution, crosstabulations with chi-Square tests were conducted for cluster membership with relevant Sociodemographic characteristics. The result is shown in Table 5.

When the positive-negative image of ageing cluster membership was cross-tabulated with the variables of residence location, marital status, working status, living arrangement, neighborhood relationship, chronic illness, and daily activities, we observed significant differences between the actual and expected values. This indicates that elderly people living in rural areas, married, members of extended families, with less chronic illnesses, better neighborhood relationships, and showing greater interests in daily activities are more likely to be clustered into the group with a positive image of ageing. In contrast, those living urban areas, singleton, relatively older in age, living in elderly homes or alone, with more chronic illnesses, worse neighborhood relationships, showing little interests in daily activities, are more likely to have a negative perception of the image of ageing. Crude evidence, thus, provided us an assurance of the validity of the clustering solution.

Different from findings of others that age and gender are influencing factors for cognitive functioning, mortality, and the hazard of dying of older Chinese [39, 46], ours do not observe such differences among different gender and age groups or socioeconomic groups in their image of ageing. In other words, except their residence location, whether elderly people perceived positively or negatively the image of ageing are not affected by their demographic characteristics but by their neighborhood relationships, whether or not suffering from chronic illnesses and how frequent they are taking daily activities. Before we went further into the logistic binary regression analysis of significant variables, we compared the means of the perception of elderly people towards their own image and that of their peers' in accordance with their residence location, age, gender, and social-economic status.

Evidence showed that there were no significant differences between male and female participants. When the means for different age groups were compared, we then observed significant differences, particularly in how they perceived their own image. Interestingly, results showed that rural participants had higher means in the perception of their 
TABLE 7: Logistic regression estimates for the effects of Sociodemographic variables with positivity of the ageing image as the dependent variables.

\begin{tabular}{|c|c|c|c|c|}
\hline \multirow{3}{*}{ Independent variables } & \multicolumn{4}{|c|}{ Negative image of ageing } \\
\hline & Step 1 & Step 2 & Step 3 & Step 4 \\
\hline & $\begin{array}{l}\text { Adjusted odds ratio } \\
\qquad(95 \% \mathrm{CI})\end{array}$ & $\begin{array}{l}\text { Adjusted odds ratio } \\
(95 \% \mathrm{CI})\end{array}$ & $\begin{array}{l}\text { Adjusted odds ratio } \\
(95 \% \mathrm{CI})\end{array}$ & $\begin{array}{c}\text { Adjusted odds ratio } \\
(95 \% \mathrm{CI})\end{array}$ \\
\hline \multicolumn{5}{|l|}{ Illness (severe) } \\
\hline No illness & $\begin{array}{c}0.165^{* * *} \\
(0.093-0.295)\end{array}$ & $\begin{array}{c}0.158^{* * *} \\
(0.087-0.286)\end{array}$ & $\begin{array}{c}0.169^{* * *} \\
(0.093-0.308)\end{array}$ & $\begin{array}{c}0.163^{* * *} \\
(0.088-0.299)\end{array}$ \\
\hline Moderate & $\begin{array}{c}0.344^{* * *} \\
(0.194-0.610) \\
\end{array}$ & $\begin{array}{c}0.326^{* * *} \\
(0.181-0.586) \\
\end{array}$ & $\begin{array}{c}0.354^{* *} \\
(0.196-0.640) \\
\end{array}$ & $\begin{array}{c}0.351^{* *} \\
(0.193-0.636) \\
\end{array}$ \\
\hline \multicolumn{5}{|l|}{ Daily activity (active) } \\
\hline Inactive & & $\begin{array}{c}3.577^{* * *} \\
(1.799-7.114)\end{array}$ & $\begin{array}{c}3.715^{* * *} \\
(1.851-7.455)\end{array}$ & $\begin{array}{c}3.573 * * * \\
(1.747-7.309)\end{array}$ \\
\hline Moderate & & $\begin{array}{c}2.329 * * * \\
(1.486-3.650)\end{array}$ & $\begin{array}{c}2.448^{* * *} \\
(1.550-3.866)\end{array}$ & $\begin{array}{c}2.420^{* * *} \\
(1.519-3.855)\end{array}$ \\
\hline \multicolumn{5}{|l|}{ Urban-rural residence (rural) } \\
\hline Urban & & & $\begin{array}{c}1.868^{* * *} \\
(1.209-2.887) \\
\end{array}$ & $\begin{array}{c}2.128^{* *} \\
(1.357-3.337) \\
\end{array}$ \\
\hline \multicolumn{5}{|l|}{ Marital status (married) } \\
\hline Single & & & & $\begin{array}{c}5.737^{* *} \\
(1.956-16.831)\end{array}$ \\
\hline Widowed & & & & $\begin{array}{c}1.310 \mathrm{NS} \\
(0.795-2.160) \\
\end{array}$ \\
\hline \multicolumn{5}{|l|}{ Working status (doing other things) } \\
\hline Retired or no longer working & & & & NS \\
\hline Still employed & & & & NS \\
\hline \multicolumn{5}{|c|}{$\begin{array}{l}\text { Living arrangement (with more than one } \\
\text { generation) }\end{array}$} \\
\hline Elderly home & & & & NS \\
\hline Alone & & & & NS \\
\hline Only with spouse & & & & NS \\
\hline \multicolumn{5}{|l|}{ Neighbourhood relationship (good) } \\
\hline Bad & & & & NS \\
\hline Normal & & & & NS \\
\hline Omnibus tests of model coefficient & $43.418^{* * *}$ & $63.266^{* * *}$ & $71.930 * * *$ & $83.868^{* * *}$ \\
\hline Hosmer and Lemeshow test $\left(\chi^{2}\right)$ & $0.000(P=1.000)$ & $0.715(P=.982)$ & $1.944(P=.963)$ & $7.571(P=.473)$ \\
\hline-2 Log likelihood & 550.134 & 530.286 & 522.309 & 509.400 \\
\hline Cox \& Snell $R^{2}$ & 0.094 & 0.134 & 0.150 & 0.174 \\
\hline Nagelkerke $R^{2}$ & 0.127 & 0.181 & 0.202 & 0.235 \\
\hline
\end{tabular}

$P<.001^{* * *} ; P<.01^{* *} ; P<.05^{*}$.

peers' image though when it comes to how they perceive themselves, urban participants appeared to have a slightly higher, though not significant, mean score than rural. In contrast, social-economic status seemed to exert an influence only on how participants perceive themselves but not how they perceive their peers (Table 6).

3.3. Multivariate Analysis. To ascertain the significance of the variables that are closely related to whether or not our participants were assigned to the positive or the negative group, especially in a multivariate context, we further conducted binary logistic regression to validate our findings. We specified forward stepping as the way in which SPSS should build its regression equation. Results are presented in Table 7.

SPSS automatically ran four steps in our regression analysis. An initial step showed that compared to participants suffering from most chronic illnesses, those healthy ones with no chronic illness or with only moderate illnesses were found to be associated with significantly fewer signs of a negative 
image about themselves $(\mathrm{OR}=0.165, P<.001 ; \mathrm{OR}=0.344$, $P<.001)$. In the second step, results showed that compared to their active counterparts, participants with no or moderate interests in taking daily activities had significantly higher chance of perceiving their image negatively $(\mathrm{OR}=3.577$, $P<.001 ;$ OR $=2.329, P<.001)$. In the third step, besides the influence of illness and daily activities, we observed that compared to the rural participants, those living in urban areas were more likely to have negative views $(\mathrm{OR}=1.868$, $P<.001)$. In the last step, results showed that illnesses, daily activities, residence location, and marital status were significant predictors of a negative/positive image. Hence, elderly people who are living in rural areas, married, having less chronic illnesses, and showing more interests in taking daily activities were identified as potent risk characteristics. The predicting directions of these independent variables in the binary regression analysis were quite consistent with those in previous cross-tabulation $\chi^{2}$ tests. However, three variables, namely, working status, living arrangement, and neighborhood relationships, did not retain their statistical significance in the multivariate context; their impact on the elderly people's image of ageing seemed to have been suppressed by other stronger predictive effects. In other words, when other variables are controlled, their predictive power gets diminished.

The change in Cox \& Snell $\mathrm{R}$ and Nagelkerke $\mathrm{R}$ indicated that a higher percent of variance had been leveled from Step 1 to Step 4 in the analysis. And these two values in the model were $17.4 \%$ and $23.5 \%$, respectively. Hosmer and Lemeshow's goodness of fit statistic was greater than 0.05 , implying that the model's estimates fit the data at an acceptable level. The $-2 \log$ likelihood has decreased from 550.134 to 509.400 gradually from the first step to the last, whilst the significant changes in the final model, compared to the base ones, indicate that it is a better model fit. From the practical perspective, the final model entitles us a twothird chance to correctly classify our participants, as for their perception of the image of ageing, into either the negative or the positive group, showing acceptable predictive accuracy.

\section{Discussions}

The purpose of this study is to validate Levy et al.'s [29] Image of Ageing Scale as it is applied in a Chinese context, and we called this the Revised Chinese Version of Levy et al's Image of Ageing Scale (IAS-C). Once IAS-C is confirmed to reach acceptable reliability and validity, we then used the scale to identify some of the Sociodemographic factors that would generally be held responsible for the perception of a positive image among the elderly. With the help of various statistical analytical tools, our final objective is to detect the Sociodemographic factors that are closely associated with making elderly people perceive themselves and their peers positively.

Our validation results confirmed that IAS-C is a psychometrically sound instrument for use in researching on the image of ageing among the Chinese elderly. The confirmatory factor analysis supported the five-factor model with 14 items, as suggested by the exploratory factor analysis. And the results showed that IAS-C has good psychometric properties. The five-factor structure, so confirmed, included almost all the important components of the ageing process identified in previous studies. For instance, in Rowe and Kahn's [4] study, successful aging was considered as a multidimensional process, encompassing the avoidance of disease and disability, the maintenance of high physical and cognitive function, and sustained engagement in social and productive activities. Similarly, in another study on Hong Kong Chinese people's views about "positive aging," participants also suggested that having a positive life attitude, good health, and active engagement in activities are said to be important elements of positive ageing [5].

Using the scores of the above-confirmed five important components of the perception of both their own image and that of their peers as clustering variables, a two-step cluster analysis was conducted. A model composed of two clusters was thus obtained $(\mathrm{BIC}=8926)$. Cluster 1 residents $(n=$ 180 ) were featured by possessing a positive image whilst cluster 2 residents $(n=265)$ possessed a negative image. The logistic results further revealed that such characteristics as working status, living arrangement, and neighborhood relationships lost their statistical significance in the multivariate contexts. On the other hand, participants who were living in urban areas, single, having severe chronic illnesses, and showing little interests in taking daily activities were identified as significant risk characteristics in making elderly people having a negative image. The differences that exist between urban and rural older residents lend support, therefore, to the hypothesis that modernization often represents an end of the privileged roles and venerated status enjoyed by elderly people [17]. Based on the findings of the present study, the following suggestions are made for planners and policy makers in Chinese communities to take appropriate measures to help foster a positive image among the elderly.

(i) Findings of our study clearly indicate that elderly people who are in good health and have fewer illnesses would most likely have a positive image of themselves and that of their peers. Hence, good health is the first station to successful ageing. We suggest that governments in Chinese communities re-examine their existing health protection schemes for their senior citizens, especially those living in rural areas, and we regard this as the most effective way to ensure elderly people not regarding themselves as burdens on their families and the society.

(ii) Secondly, our study confirms, once again, that family ownership and family support is a potent influencing factor in shaping the perception of elderly people about themselves and that of their peers. Our findings clearly indicate that elderly people who feel happy and secure in their homes usually take a positive view of themselves. Our suggestion for governments in Chinese communities is to uphold, as far as possible, certain traditional values, like respecting the old and that family networks should be strengthened through the enactment of appropriate support measures in the community. 
(iii) Thirdly, we found in our study that elderly people who are keeping a close relationship with their neighbors and showing greater interests in daily activities are often those who have a positive perception of themselves as well as their peers. How to help elderly people maintain an active life is thus a question that policy makers must consider. We suggest that jobs be provided for elderly people who are able to work. Such kind of jobs should best be of a part-time nature so that elderly people would not be overburdened. In our interviews with our participants, we found not a few of them, especially those living in urban areas, were interested in volunteer services, and as long as opportunities were available, they were willing to give their time and energy for the benefit of the community. We believe that this might be the best way to help elderly people maintain a positive image.

(iv) Finally, our study reveals that Chinese elderly people have the tendency to self-enhance by perceiving more positively their own image than that of their peers, rather inconsistent with the common belief that they should be modest and deference, in accordance with the Confucian tradition. One possible explanation for this is that Chinese elderly people are now often negatively perceived as "outdating in their knowledge and skills," "can't catch up with the times," "stubborn and useless," and, hence, in fighting back, they want to project a positive image of themselves, instead of being negatively stereotyped [47]. To rectify this, our suggestion is that public education about ageing must be mounted and programs must reflect both the positive and negative aspects of the process; only in this way, people will have a better understanding of the elderly living among them.

In conclusion, what we have achieved in our study is, first, the construction of IAS-C, which is applicable to Chinese communities. The other achievement is the identification of a number of Sociodemographic factors which are statistically significant in shaping the perception of elderly people about themselves and that of their peers. Based on these findings, we are able to make suggestions for policy makers in Chinese communities to promote a positive image among the elderly.

\section{References}

[1] Population Division, World Population Ageing: 1950-2050, Department of Economic and Social Affairs, United Nations, New York, NY, USA, 2006.

[2] China Statistical Bureau, China Statistical Yearbook, China Statistics Press, Beijing, China, 2009.

[3] E. Calvo and J. B. Williamson, "Old-age pension reform and modernization pathways: lessons for China from Latin America," Journal of Aging Studies, vol. 22, no. 1, pp. 74-87, 2008.

[4] J. W. Rowe and R. Kahn, "Successful Ageing," Gerontologists, vol. 37, no. 4, pp. 433-440, 1997.

[5] A. M.-L. Chong, S.-H. Ng, J. Woo, and A. Y.-H. Kwan, "Positive ageing: the views of middle-aged and older adults in
Hong Kong," Ageing and Society, vol. 26, no. 2, pp. 243-265, 2006.

[6] T. M. Hess, C. Auman, S. J. Colcombe, and T. A. Rahhal, "The impact of stereotype threat on age differences in memory performance," Journals of Gerontology B, vol. 58, no. 1, pp. P3P11, 2003.

[7] B. Levy and E. Langer, "Aging free from negative stereotypes: successful memory in China and among the American deaf," Journal of Personality and Social Psychology, vol. 66, no. 6, pp. 989-997, 1994.

[8] B. Levy, M. D. Slade, and T. M. Gill, "Hearing decline predicted by elder's stereotypes," Journals of Gerontology B, vol. 61, no. 2, pp. P82-P87, 2006.

[9] B. Levy, O. Ashman, and I. Dror, "To be or not to be: the effects of aging stereotypes on the will to live," Omega, vol. 40, no. 3 , pp. 409-420, 2000.

[10] J. M. Hausdorff, B. R. Levy, and J. Y. Wei, "The power of ageism on physical function of older persons: reversibility of age-related gait changes," Journal of the American Geriatrics Society, vol. 47, no. 11, pp. 1346-1349, 1999.

[11] D. W. Lai, "Older chinese' attitudes toward aging and the relationship to mental health: an international comparison," Social Work in Health Care, vol. 48, no. 3, pp. 243-259, 2009.

[12] B. Levy, M. D. Slade, S. R. Kunkel, and S. V. Kasl, "Longevity increased by positive self-perceptions of aging," Journal of Personality and Social Psychology, vol. 83, no. 2, pp. 261-270, 2002.

[13] S. E. Taylor and J. D. Brown, "Illusion and well-being: a social psychological perspective on mental health," Psychological Bulletin, vol. 103, no. 2, pp. 193-210, 1988.

[14] S. E. Taylor and J. D. Brown, "Positive illusions and well-being revisited: separating fact from fiction," Psychological Bulletin, vol. 116, no. 1, pp. 21-27, 1994.

[15] H. Zhou, Y. J. Zhong, X. F. Wang, X. Zhang, and J. F. Wang, “A survey of influence of self-concept on life quality of emptynest elderly (Kongchao laoren ziwo gainian dui shengcun zhiliang yingxiang de diaocha)," Nursing Research, vol. 22, no. 7, pp. 1809-1810, 2008.

[16] S. S. Tobin, Preservation of the Self in the Oldest Years, Springer, New York, NY, USA, 1999.

[17] D. O. Cowgill and L. D. Holmes, Aging and Modernization, Appleton-Century-Crofts, New York, NY, USA, 1972.

[18] B. Gunter, Understanding the Older Consumer: The Grey Market, Routledge, New York, NY, USA, 1998.

[19] E. B. Palmore, Ageism: Negative and Positive, Springer, New York, NY, USA, 1990.

[20] N. Chow and X. Bai, "Modernization and its impact on Chinese older people's perception of their own image and status," International Social Work. In press.

[21] Y. B. Zhang, J. Harwood, A. Williams, V. Ylänne-Mcewen, P. M. Wadleigh, and C. Thimm, "The portrayal of older adults in advertising: a cross-national review," Journal of Language and Social Psychology, vol. 25, no. 3, pp. 264-282, 2006.

[22] D. T. Tsai and R. A. Lopez, "The use of social supports by elderly chinese immigrants," Journal of Gerontological Social Work, vol. 29, no. 1, pp. 77-94, 1997.

[23] X. Bai and N. Chow, "The impact of modernization and globalization on the perception of the Chinese elderly towards their image and status," Global Studies Journal, vol. 3, no. 2, pp. 43-54, 1997.

[24] S. Chiu and S. Yu, "An excess of culture: the myth of shared care in the Chinese community in Britain," Ageing and Society, vol. 21, no. 6, pp. 681-699, 2001. 
[25] N. Chow, "The practice of filial piety among the Chinese in Hong Kong," in Elderly Chinese in Pacific Rim Countries: Social Support and Integration, I. Chi, N. L. Chappell, and J. Lubben, Eds., pp. 125-136, Hong Kong Universities Press, Hong Kong, 2001.

[26] N. Chow, "Asian value and aged care," Geriatrics and Gerontology International, vol. 4, pp. 521-525, 2004.

[27] A. E. Joseph and D. R. Phillips, "Ageing in rural China: impacts of increasing diversity in family and community resources," Journal of Cross-Cultural Gerontology, vol. 14, no. 2, pp. 153$168,1999$.

[28] A. Boduroglu, C. Yoon, T. Luo, and D. C. Park, "Age-related stereotypes: a comparison of American and Chinese cultures," Gerontology, vol. 52, no. 5, pp. 324-333, 2006.

[29] B. Levy, S. V. Kasl, and T. M. Gill, "Image of aging scale," Perceptual and Motor Skills, vol. 99, no. 1, pp. 208-210, 2004.

[30] J. Cairney and N. Krause, "The social distribution of psychological distress and depression in older adults," Journal of Aging and Health, vol. 17, no. 6, pp. 807-835, 2005.

[31] L. K. George, R. Landerman, D. G. Blazer, and J. C. Anthony, "Cognitive impairment," in Psychiatric Disorders in America: The Epidemiologic Catchment Area Study, L. N. Robins and D. A. Reiger, Eds., pp. 291-327, Free Press, New York, NY, USA, 1991.

[32] J. R. Kahn and E. M. Fazio, "Economic status over the life course and racial disparities in health," Journals of Gerontology $B$, vol. 60, pp. 76-84, 2005.

[33] L.-J. Liu and Q. Guo, "Loneliness and health-related quality of life for the empty nest elderly in the rural area of a mountainous county in China," Quality of Life Research, vol. 16, no. 8, pp. 1275-1280, 2007.

[34] CNHUBEI, "Wuhan Elderly Population'” January 2010, http: //www.chinanews.com.cn/jk/lryys/news/2009/03-31/1625769 .shtml.

[35] Provincial Statistical Bureau of Hubei, Hubei Statistical Yearbook 2009, China Statistics Press, Beijing, China, 2010.

[36] R. D. Mason, D. A. Lind, and W. G. Marchal, Statistics: An introduction, International Thomson Publishing, CA, USA, 1998.

[37] K. R. Smith and C. D. Zick, "Linked lives, dependent demise? Survival analysis of husbands and wives," Demography, vol. 31, no. 1, pp. 81-93, 1994.

[38] G. P. Mineau, K. R. Smith, and L. L. Bean, "Historical trends of survival among widows and widowers," Social Science and Medicine, vol. 54, no. 2, pp. 245-254, 2002.

[39] D. L. Poston Jr. and H. Min, "The effects of sociodemographic factors on the hazard of dying among Chinese oldest old," in Health longevity in China, Y. Zeng, D.L. Poston Jr., D. A. Vlosky, and D. Gu, Eds., pp. 121-131, Springer, New York, NY, USA, 2008.

[40] E. Grundy, A. Bowling, and M. Farquhar, "Social support, life satisfaction and survival at older ages," in Proceedings of Conference on Health and Mortality Trends among Elderly Populations: Determinants and Implications, IUSSP, Sendai City, Japan, June 1993.

[41] R. P. Ang and V. S. Huan, "Academic expectations stress inventory: development, factor analysis, reliability, and validity," Educational and Psychological Measurement, vol. 66, no. 3, pp. 522-539, 2006.

[42] J. F. Hair, W. C. Black, B. J. Babin, and R. E. Anderson, Multivariate Data Analysis: A Global Perspective, Pearson Education, Delhi, India, 7th edition, 2010.

[43] T. Jirapramukpitak, N. Darawuttimaprakorn, S. Punpuing, and M. Abas, "Validation and factor structure of the Thai version of the EURO-D scale for depression among older psychiatric patients," Aging and Mental Health, vol. 13, no. 6, pp. 899-904, 2009.

[44] SPSS, "The SPSS TwoStep Cluster Component: a scalable component enabling more efficient customer segmentation," White Paper Technical Report, SPSS, 2001.

[45] J. R. Chambers and P. D. Windschitl, "Biases in social comparative judgments: the role of nonmotivated factors in above-average and comparative-optimism effects," Psychological Bulletin, vol. 130, no. 5, pp. 813-838, 2004.

[46] J. Ao, Risk factors of cognitive functioning of the Chinese oldestold, M.S. thesis, Peking University, 2004.

[47] M. Pinquart, "Good news about the effects of bad old-age stereotypes," Experimental Aging Research, vol. 28, no. 3, pp. 317-336, 2002. 


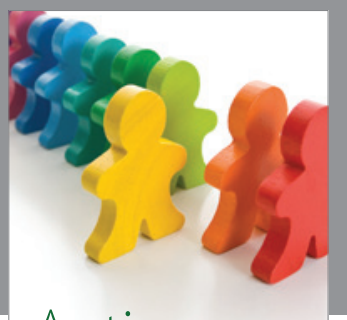

Autism

Research and Treatment
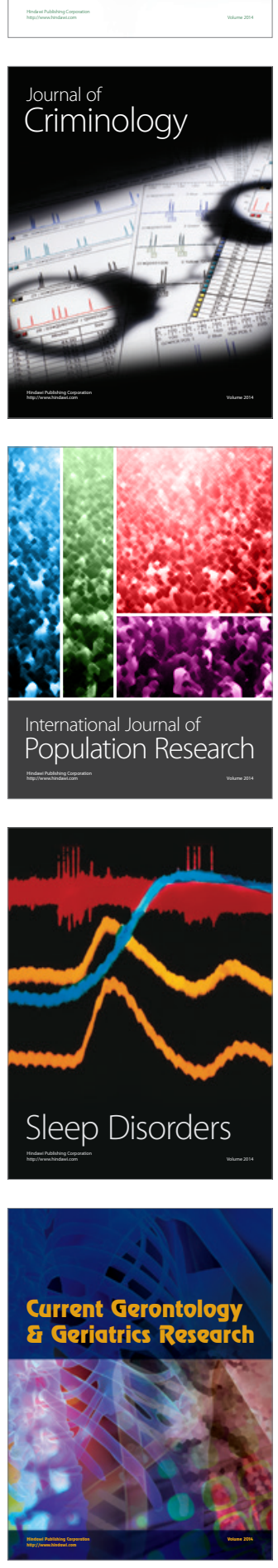
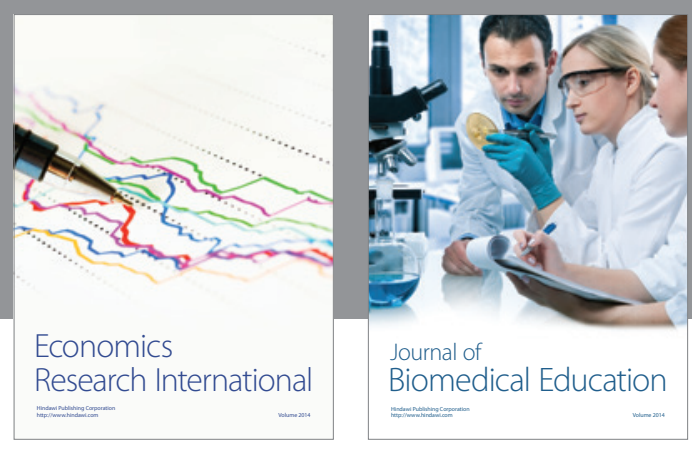

Journal of

Biomedical Education

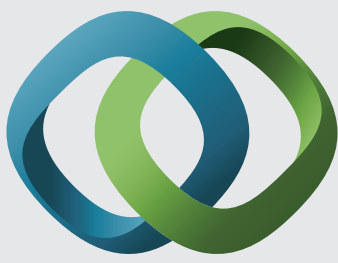

\section{Hindawi}

Submit your manuscripts at

http://www.hindawi.com
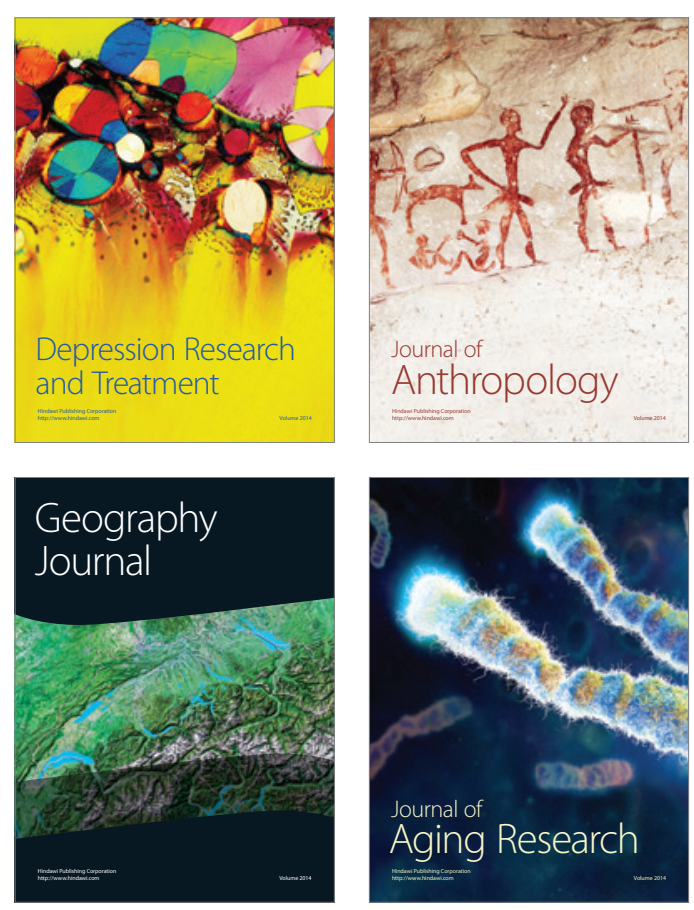

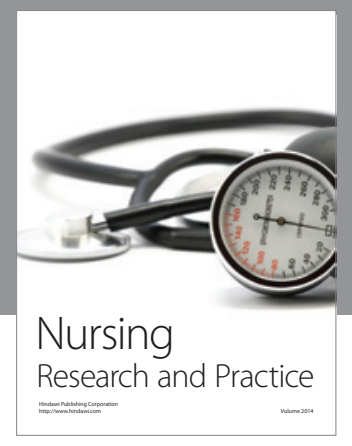

Nursing

Research and Practice

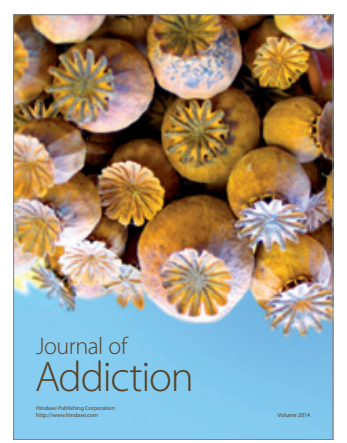

Child Development

Research

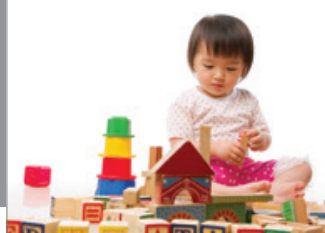

迥
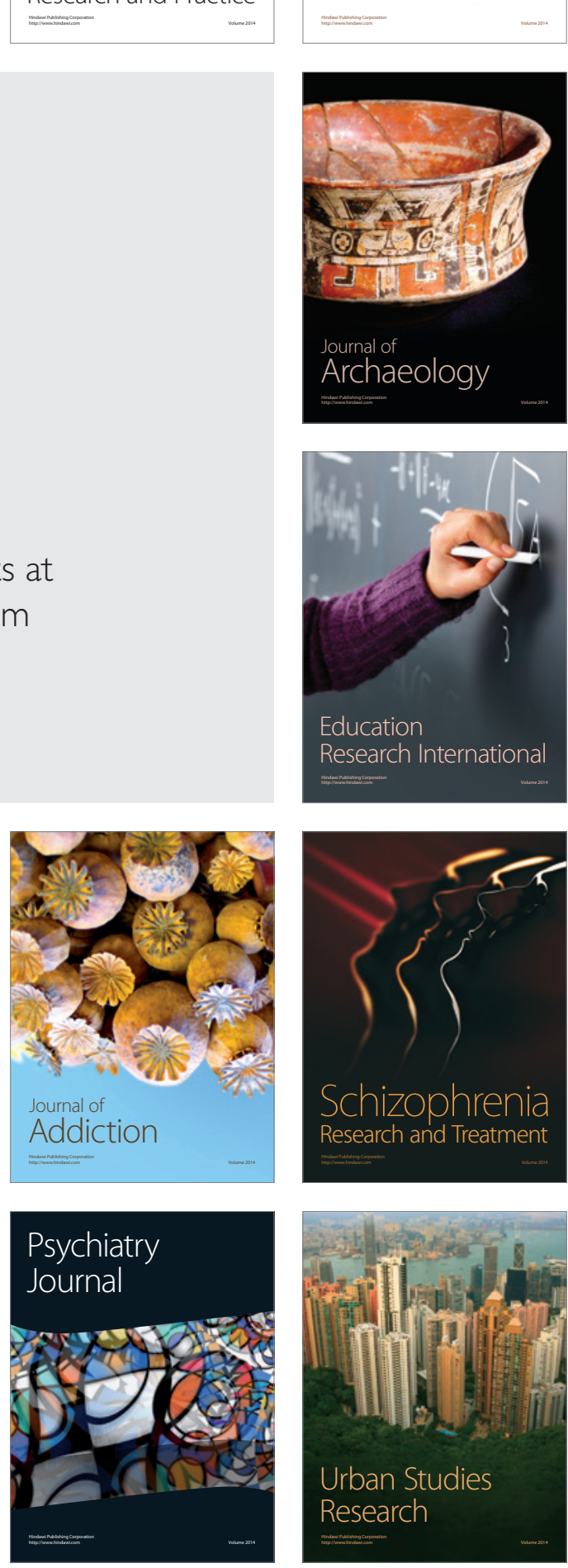